$\mathbf{R}_{\text {ESEARCH }} \mathbf{P}_{\text {APER }} \longrightarrow$ FOOD SCIENCE.

www.researchjournal.co.in

Volume 9 | Issue 1 | April, 2018 | 117-120

DOI : 10.15740/HAS/FSRJ/9.1/117-120

\title{
Anti-nutritional factors and mineral content of different oat (Avena sativa L.) varieties
}

\author{
Bhawna Mehta and Sudesh $\mathbf{J}_{\text {ood }}$
}

\begin{abstract}
Five oat varieties namely HJ-8, HFO-114, OS-6, OS-346 and KENT were examined for their antinutritional factors and total and available minerals. The results showed that anti-nutritional factors like phytic acid and polyphenols were found highest (137.33 and $231.80 \mathrm{mg} / 100 \mathrm{~g})$ in OS-6 variety and lowest (112.80 and $203.60 \mathrm{mg} / 100 \mathrm{~g})$ in OS-346 variety. OS-346 variety contained significantly higher calcium, phosphorus, magnesium, iron and zinc content as compared to other four varieties. In vitro availability of calcium of different oat varieties varied from 42.80 to 49.16 per cent, respectively, the highest (49.16\%) being observed for OS-346 variety and the lowest (42.80\%) in OS-6 variety. In vitro availability of iron was also found maximum in OS-346 variety. Among the five oat varieties, OS-6 variety exhibited minimum (30.96\%) in vitro availability of iron and OS-346 variety showed maximum (40.70\%) in vitro availability of iron. In vitro availability of zinc varied from 31.56 to 35.82 per cent, with variety OS-6 had lowest (31.56\%) and variety OS-346 exhibited highest (35.82\%) in vitro availability of zinc. On the whole, it was concluded that the OS-346 variety was found superior than other four oat varieties used in this study.
\end{abstract}

Key Words : Oat varieties, Total and available minerals, Anti-nutritional factors

How to cite this article : Mehta, Bhawna and Jood, Sudesh (2018). Anti-nutritional factors and mineral content of different oat (Avena sativa L.) varieties. Food Sci. Res. J., 9(1): 117-120, DOI : 10.15740/HAS/FSRJ/9.1/117-120.

Author for correspondence :

Bhawna Mehta, Department of Foods and Nutrition, College of Home Science, C.C.S. Haryana Agriculture University, Hisar (Haryana) India (Email : bhawna.mehtaa2013@gmail.com)

Associate Authors' :

Sudesh Jood, Department of Foods and Nutrition, College of Home Science, C.C.S. Haryana Agriculture University, Hisar (Haryana) India 